\title{
Drone Control Using EEG
}

\author{
Dr. Priya Charles ${ }^{1}$ Aditi Sinha ${ }^{2}$ Siddhant Kulkarni ${ }^{3}$ Pranav Shah ${ }^{4}$ \\ ${ }^{1}$ Department of Electronics and Telecommunication Engineering, Dr. D. Y. Patil \\ Institute of Engineering, Management \& Research, \\ Akurdi, India \\ ${ }^{2}$ Department of Electronics and Telecommunication Engineering, Dr. D. Y. Patil \\ Institute of Engineering, Management \& Research, \\ Akurdi, India \\ ${ }^{3}$ Department of Electronics and Telecommunication Engineering, Dr. D. Y. Patil \\ Institute of Engineering, Management \& Research, \\ Akurdi, India \\ ${ }^{4}$ Department of Electronics and Telecommunication Engineering, Dr. D. Y. Patil \\ Institute of Engineering, Management \& Research, \\ Akurdi, India \\ E-mail: ${ }^{1}$ hodetc@dypiemr.ac.in, ${ }^{2}$ aditisinha906@gmai.com,
siddhantpk@gmail.com, ${ }^{4}$ pranav98shah@gmail.com
}

\begin{abstract}
Artificial Intelligence and automation is the future of the world, and with continuous reduction in human effort, The project aims to develop a drone that is controlled entirely by brain waves, based on Brain-Computer Interfaces (BCI). This interface is possible using EEG. Electroencephalography (EEG) is a diagnostic test and monitoring method used to record electrical activities in the brain. The EEG has electrodes in the form of small, metal discs that are attached to the person's scalp, these detect the changes and abnormalities in the brain waves which are in the form of electrical signals. The received signals are passed through filters and different operations to extract suitable, operational signal features which are segregated on various parameters outlined for drone controls, are fed to the ML model which will classify the input, to be trained repeatedly to properly guide the drone. The desired feature results are delivered to the drone through Arduino. A drone controlled with brain waves is useful during search and rescue operations providing critical information from aerial points. A similar BCI application can be used in bionic prosthetics so that a person lacking a limb may be able to control a prosthetic simply using an EEG and EMG interface. There are limitless applications in human-to-machine interaction that will reduce the need for physical input.
\end{abstract}

Keywords: EEG, Drone control, EEG controlled drone, BCI 


\section{Introduction}

An electroencephalogram (EEG) is a test that detects electrical activity in your brain using small, metal discs (electrodes) attached to your scalp. Your brain cells communicate via electrical impulses and are active all the time, even when you're asleep.

A brain-computer interface (BCI) is a system that measures activity of the central nervous system (CNS) and converts it into artificial output that replaces, restores, enhances, supplements, or improves natural CNS output, and thereby changes the ongoing interactions between the CNS and its external or internal environment.

The term "drone" usually refers to any unpiloted aircraft. Sometimes referred to as "Unmanned Aerial Vehicles" (UAVs), these crafts can carry out an impressive range of tasks, ranging from military operations to package delivery. Drones can be as large as an aircraft or as small as the palm of your hand.

Our project combines the two mentioned that is EEG with Drones using Brain computer interface giving "DRONE CONTROL USING EEG". The Drone will be a braincontrolled drone that can fly without any physical controller, able to identify facial movements and gestures to perform different basic actions. To function, the user needs to wear the EEG headband, which will capture the brain signal in the form of electrical waves and these signals will be passed through filters and then be trained in the ML model. Using arduino in the drone, the input signal will be given followed by the action movement as the output.

\section{Literature Review}

\section{1. "Brainwave Controlled Wheelchair",}

Miss. Reshma Arote, Miss. Komal Nawale, Miss. Monika Shinde, Student, BE Computer, Prof. P.

A. Bansode, Prof. V. B. Bhamare, Assistant Professor,

Department Of Computer Engineering, SVCET, Rajuri

Published in: Imperial Journal of Interdisciplinary Research (IJIR),Vol-3, Issue-12, (2017).

The main part of the project is an EEG sensor which is placed on the head. Neurosky sensor has been used here for it has phase sensor having only one electrode on the frontal lobe of the brain and ground of the sensor is attached to the ear. Along with accelerometer sensor which is used to give the direction to the wheelchair. Both the sensors (Neurosky and Accelerometer) are connected to 2 Arduino boards for better connection through wired communication. Connection between hardware and software is established using RF transmitter and receiver. MATLAB and Arduino software has been used where MATLAB is used to receive signals from sensors and process them to set input commands. These commands are sent to the hardware base via Arduino. 


\section{2. "Prosthetic arm Controller Based on Brainwaves Spectrum EEG Sensor",}

Subrata Mukhopadhyay, Senior Member, IEEE, EEE/ECE Department, Guru Tegh Bahadur Institute of Technology

Published in: 2014 6th IEEE Power India International Conference (PIICON)

The paper presents how there can be interconnected two ubiquitous elements nowadays. On one hand, the drones, which are increasingly present and integrated into more and more fields of activity, beyond the military applications they come from, moving towards entertainment, realestate, delivery and so on. On the other hand, unconventional man-machine interfaces, which are generous topics to explore now and in the future. Of these, we chose brain computer interface (BCI), which allows human-machine interaction without requiring any moving elements. The research consists of mathematical modeling and numerical simulation of a drone and a BCI. Then there is an application using a Parrot mini-drone and an Emotiv Insight BCI.

\section{3. "Brain Controlled Robot Car",}

Lin Zhou, Furong Li, Senior Member, IEEE,

Chenghong Gu, ZechunHu, and Simon Le Blond, Member, IEEE

Published in: IEEE Transactions on Smart Grid (Volume-5, Issue-2, March 2014)

Noninvasive brain-computer interface (BCI) decodes brain signals to understand user intention. Recent advances have been developed for the BCI-based drone control system as the demand for drone control increases. Especially, drone swarm control based on brain signals could provide various industries such as military service or industry disaster. This paper presents a prototype of a brain-swarm interface system for a variety of scenarios using a visual imagery paradigm. We designed the experimental environment that could acquire brain signals under a drone swarm control simulator environment. Through the system, we collected the electroencephalogram (EEG) signals with respect to four different scenarios. Seven subjects participated in our experiment and evaluated classification performances using the basic machine learning algorithm. The grand average classification accuracy is higher than the chance level accuracy. Hence, we could confirm the feasibility of the drone swarm control system based on EEG signals for performing high-level tasks.

\section{4. "Brain Wave Controlled Drone",}

Shubham B. Parsewar, Pooja P.Polawar, Gayatree V. Paul, Department of Electronics and Communication Engineering, G. H. Raisoni Institute of Engineering and Technology Wagholi, Pune, Maharashtra, India Published in: International Journal of Innovations in Engineering and Technology (IJIET), Volume-6, Issue-2, December-2015.

Corruption has been around for a very long time and will remain in the future unless governments can figure out effective ways to combat it (Mauro 1997). E-government is increasingly used to improve transparency in the government sector and to combat against corruption .E-government is being implemented in more areas of government administration for both the local and national 
levels worldwide. E-government system developed to reduce corruption. The aim of this paper is to organize and summarize existing theoretical and empirical work on corruption with a view identifying opportunities for further research. Computerization can help in modernizing the PDS. The southern states as usual have led the way on many reforms intended to address the issues above, and increasingly even poorer states have introduced changes in policies and implementation mechanisms to address the problems of PDS. This paper discusses strategy adapted in using ICT to control diversion and leakage in the delivery mechanism and its successful application in computerization of food grain supply chain. As an outcome of the project, 0.78 Million farmers have received computer generated cheques without any delay. Citizen involvement in the system has been increased in monitoring PDS. Here efforts from our side are done to overcome one of the corruption problem involve in ration distribution system through a kind of electrodynamics web template where distribution of ration products like kerosene, rice, wheat etc. at rural and urban areas, will be checked, monitored and controlled with filtering the problem of corruption and adulteration.

\section{5. "Controlling electrical devices with human brainwaves",}

S.Valarmathy, R.Ramani, S.Selvaraju, G.Ramachandran, Associate Professors /ECE, Fahim Akhtar, Student /ETCE,

V.M.K.V Engg College, Salem, TN, India

Published in: I.J. Intelligent Systems and Applications, October-2013.

Now a day ration card is very important for every home and used for various field such as family members details, to get gas connection, it act as address proof for various purposes etc. All the people having a ration card to buy the various materials (sugar, rice, oil, kerosene, etc) from the ration shops. But in this system having two draw backs, first one is weight of the material may be inaccurate due to human mistakes and secondly, if not buy the materials at the end of the month, they will sale to others without any intimation to the government and customers. In this paper, proposed an Automatic Ration Materials Distribution Based on GSM (Global System for Mobile) and RFID (Radio Frequency Identification) technology instead of ration cards. To get the materials in ration shops need to show the RFID tag into the RFID reader, then controller check the customer codes and details of amounts in the card. After verification, these systems show the amount details. Then customer need to enter they required materials by using keyboard, after receiving materials controller send the information to government office and customer through GSM technology. In this system provides the materials automatically without help of humans.

\section{6. "Drone Control based on Mental Commands and Facial Expressions",}

A.N.Madur, P.N.Matte,

Department of Electronics and Telecommunication Engineering,

Published in: International Journal of Engineering Research and Technology (IJERT), Vol-2, Issue-10, October-2013

Today's public distribution involves corruption and leakage of goods. Because of this, the food article doesn't reach to poor people completely. It happens because the PDS system is manual. 
Actual quality food doesn't reach to people, even they didn't know quantity of food assign to them by government. In this paper we propose to replace manual PDS with smart PDS at ration shop. The apparatus we are designing is cost effective and can prove helpful to Govt. of India's PDS System and to various other disciplines. In terms of feasibility it is a vast concept and an interesting task to perform and totally feasible in all aspects technical as well as other. Automation in the distribution field allows utilities to implement flexible control of distribution systems, which can be used to enhance efficiency, reliability and quality of service.

Table 1. Comparison Table

\begin{tabular}{|c|c|c|c|c|c|}
\hline $\begin{array}{l}\text { Sr. } \\
\text { No. }\end{array}$ & $\begin{array}{l}\text { Title of } \\
\text { paper }\end{array}$ & Author Name & $\begin{array}{c}\text { Year of } \\
\text { Publication }\end{array}$ & Methodology & Advantage \\
\hline 1 & $\begin{array}{l}\text { Brain } \\
\text { Controlled } \\
\text { Wheelchair }\end{array}$ & $\begin{array}{l}\text { Ms. Anushree } \\
\text { Anant Kittur } \\
\text { Mr. Saket Raju } \\
\text { Badge } \\
\text { Mr.Rohit } \\
\text { Arvind } \\
\text { Deshmukh } \\
\text { Mrs. Varsha K } \\
\text { Patil }\end{array}$ & 2018 & $\begin{array}{l}\text { 1. The main part of the } \\
\text { project is EEG sensor } \\
\text { which is placed on the } \\
\text { head. Neurosky sensor } \\
\text { has been used here for it } \\
\text { has phase sensor having } \\
\text { only one electrode on } \\
\text { frontal lobe of the brain } \\
\text { and ground of the sensor } \\
\text { is attached to the ear. } \\
\text { Along with accelerometer } \\
\text { sensor which is used to } \\
\text { give the direction to the } \\
\text { wheelchair. } \\
\text { 2. Both the sensors } \\
\text { (Neurosky and } \\
\text { Accelerometer) } \\
\text { connected to } 2 \text { Arduino } \\
\text { boards for better } \\
\text { connection through wired } \\
\text { communication. } \\
\text { Connection between } \\
\text { hardware and software is } \\
\text { established using RF } \\
\text { transmitter and receiver. } \\
\text { MATLAB and Arduino } \\
\text { software has been used } \\
\text { where MATLAB is used } \\
\text { to receive signals from } \\
\text { sensors and process them } \\
\text { to set input commands. } \\
\text { these commands are sent } \\
\text { to the hardware base via }\end{array}$ & $\begin{array}{l}\text { It is useful for the paralyzed } \\
\text { and handicap people. } \\
\text { Usage of Non-Invasive BCI } \\
\text { causing low damage to } \\
\text { human body. }\end{array}$ \\
\hline
\end{tabular}




\begin{tabular}{|c|c|c|c|c|c|c|}
\hline & & & & & Arduino. & \\
\hline 2 & $\begin{array}{l}\text { Prosthetic Arm } \\
\text { Controller } \\
\text { Based On } \\
\text { Brainwave } \\
\text { Spectrum EEG } \\
\text { Sensor }\end{array}$ & $\begin{array}{l}\text { J. Utama } \\
\text { G. Palada }\end{array}$ & 2017 & 1 & $\begin{array}{l}\text { The project uses EEG } \\
\text { sensor-NeuroSKY } \\
\text { MindWave Mobile sensor } \\
\text { has been used here. } \\
\text { The signals are received } \\
\text { using Bluetooth dongle. } \\
\text { These signals are fed to } \\
\text { Interface- LAB VIEW for } \\
\text { processing and training to } \\
\text { interpret the motion of the } \\
\text { prosthetic hand. } \\
\text { All processing orders are } \\
\text { then sent to the } \\
\text { microcontroller (Arduino } \\
\text { UNO) to drive the } \\
\text { actuators. } \\
\text { Tests like- EEG sensor } \\
\text { analysis, Grip testing, } \\
\text { Arm movement were } \\
\text { conducted. }\end{array}$ & $\begin{array}{l}\text { EEG signals are used rather } \\
\text { than EMG for each } \\
\text { movement required different } \\
\text { EMG sensor whereas EEG } \\
\text { represents several arm } \\
\text { operations. } \\
\text { Wireless connection and } \\
\text { communication } \\
\text { established. } \\
\begin{array}{l}\text { Usage of Non-Invasive BCI } \\
\text { causing low damage to } \\
\text { human body. }\end{array}\end{array}$ \\
\hline 3 & $\begin{array}{l}\text { Brain } \\
\text { Controlled } \\
\text { Robot Car }\end{array}$ & $\begin{array}{l}\text { R. S. } \\
\text { Shekhawat } \\
\text { Rajat Sharma } \\
\text { Ravi Rao }\end{array}$ & 2014 & 1 & $\begin{array}{l}\text { The main part of the } \\
\text { project is EEG sensor } \\
\text { which is placed on the } \\
\text { head. Neurosky headset } \\
\text { provides signals like } \\
\text { meditation and attention. } \\
\text { Along with this, the eye- } \\
\text { blink signals are extracted } \\
\text { from the headset. } \\
\text { With the help of } \\
\text { Bluetooth this is used to } \\
\text { interface with the Robot } \\
\text { car. } \\
\text { Interface is organized by } \\
\text { using Arduino UNO and } \\
\text { it is also connected to the } \\
\text { computer having Arduino } \\
\text { IDE. } \\
\text { The program in the } \\
\text { Arduino analyzes the data } \\
\text { received by Bluetooth and }\end{array}$ & $\begin{array}{l}\text { Less complex and cheap. } \\
\text { Complete wireless motor car. } \\
\text { Usage of Non-Invasive BCI } \\
\text { causing low damage to } \\
\text { human body. }\end{array}$ \\
\hline
\end{tabular}




\begin{tabular}{|c|c|c|c|c|c|c|}
\hline & & & & 6. & $\begin{array}{l}\text { accordingly generates } \\
\text { outputs on the terminals } \\
\text { which are already stored } \\
\text { in the program. } \\
\text { Brain signal responds to } \\
\text { take move while } \\
\text { concentration leads to } \\
\text { acceleration. } \\
\text { Analysis of the raw data } \\
\text { is interpreted using } \\
\text { MATLAB and } \\
\text { LABVIEW. }\end{array}$ & \\
\hline 4 & $\begin{array}{l}\text { Brain Wave } \\
\text { Controlled } \\
\text { Drone }\end{array}$ & $\begin{array}{l}\text { Himanshu } \\
\text { Salhotra } \\
\text { Yogesh Tickoo } \\
\text { Saksham } \\
\text { Gandotra } \\
\text { Divya Jain }\end{array}$ & 2018 & 5. & $\begin{array}{l}\text { The project starts with a } \\
\text { brain headset basically } \\
\text { used for reading the brain } \\
\text { waves. } \\
\text { The frontal part of the } \\
\text { scalp is attached to } \\
\text { electrodes which read and } \\
\text { store the electric activities } \\
\text { of the brain. } \\
\text { Since the signals received } \\
\text { are in analog form, there } \\
\text { is a need of conversion of } \\
\text { these signals to digital } \\
\text { form. } \\
\text { For this a conditioning } \\
\text { circuit is used which maps } \\
\text { the signal at } 512 \text { samples } \\
\text { per second. } \\
\text { The signals are then } \\
\text { transmitted to the drone } \\
\text { via Bluetooth. } \\
\text { The drone has a built in } \\
\text { Bluetooth module } \\
\text { connected to a } \\
\text { microcontroller. } \\
\text { These signals are then } \\
\text { processed and sent to the } \\
\text { ESC(Electronic Speed } \\
\text { Controller) } \\
\text { to which }\end{array}$ & $\begin{array}{l}\text { The BCI helps people to } \\
\text { make use of the devices and } \\
\text { applications through their } \\
\text { mental activities reducing } \\
\text { physical efforts. } \\
\text { Since each brain wave is } \\
\text { unique so it has high security. }\end{array}$ \\
\hline
\end{tabular}




\begin{tabular}{|c|c|c|c|c|c|c|}
\hline & & & & 8. & $\begin{array}{l}\text { activates the brushless } \\
\text { motors as per the } \\
\text { program. } \\
\text { This in turn helps in the } \\
\text { flight of the drone. }\end{array}$ & \\
\hline 5 & $\begin{array}{l}\text { Controlling } \\
\text { Electrical } \\
\text { Devices With } \\
\text { Human } \\
\text { Brainwaves }\end{array}$ & $\begin{array}{l}\text { Shesh Mani } \\
\text { Tiwari } \\
\text { Nikhil Panwar } \\
\text { Somendra } \\
\text { Tripathi }\end{array}$ & 2018 & 5. & $\begin{array}{l}\text { In this project brainwave } \\
\text { sensing and transmission } \\
\text { is done using the } \\
\text { Neurosky mind wave } \\
\text { mobile. } \\
\text { The system flow starts } \\
\text { with feeding raw } \\
\text { brainwaves into the } \\
\text { mindwave mobile. } \\
\text { From here the electrical } \\
\text { signals go through a series } \\
\text { of processing algorithms } \\
\text { which can be used by the } \\
\text { microcontroller. } \\
\text { The outcome of the data } \\
\text { processing is fed into the } \\
\text { microcontroller. } \\
\text { A relay is used to connect } \\
\text { the microcontroller to an } \\
\text { electrical appliance which } \\
\text { will help in locking and } \\
\text { unlocking the device. } \\
\text { To check the accuracy of } \\
\text { brainwaves it was tested } \\
\text { against varying intensities } \\
\text { of beta and gamma } \\
\text { waves. }\end{array}$ & $\begin{array}{l}\text { This project was built at a } \\
\text { very affordable price. } \\
\text { Since brainwaves didn't } \\
\text { replicate any beta or gamma } \\
\text { rays and couldn't be } \\
\text { manipulated, hence the } \\
\text { system has very high } \\
\text { security. }\end{array}$ \\
\hline 6 & $\begin{array}{l}\text { Drone Control } \\
\text { Based On } \\
\text { Metal } \\
\text { Commands } \\
\text { And Facial } \\
\text { Experssions }\end{array}$ & $\begin{array}{l}\text { Iuliana Marin } \\
\text { Myssar Jabbar } \\
\text { Hammood Al- } \\
\text { Battbootti } \\
\text { Nicolae Goga }\end{array}$ & 2018 & 3. & $\begin{array}{l}\text { The system works on BCI } \\
\text { system to control a drone. } \\
\text { The brain wave patterns } \\
\text { are indicated using the } \\
\text { Emotiv Insight EEG } \\
\text { headset for the controlling } \\
\text { of the drone. } \\
\text { The commands are }\end{array}$ & $\begin{array}{l}\text { The BCI helps people to } \\
\text { make use of the devices and } \\
\text { applications through their } \\
\text { mental activities reducing } \\
\text { physical efforts. } \\
\text { Since each brain wave is } \\
\text { unique so it has high security. }\end{array}$ \\
\hline
\end{tabular}




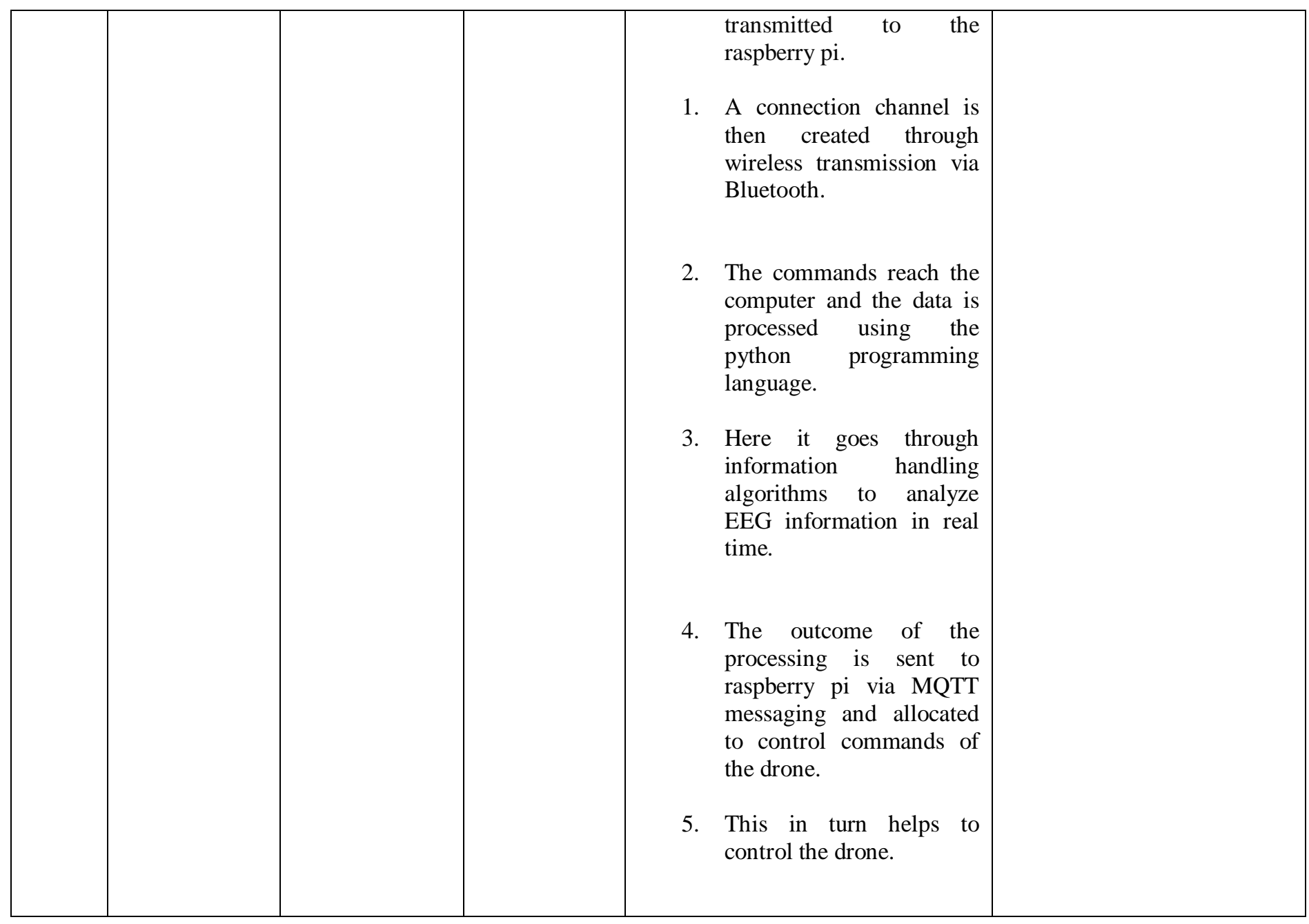

\section{Problem Identified}

Realise the potential of the brain to human interface by which the effort humans have to take minimizes, upscaling the potential usage in bionic arms, artificial limbs, hormone control and body function control.

\section{Proposed System}

The system we have proposed we would be using an EEG headset to measure the brainwaves, then we would transmit them to a desktop device where we would be applying filters to the brainwave signal collected so as to get desired type of signal which can be passed through a machine learning model. 
The said ML model will be trained beforehand with the help of 10 test subjects to achieve a high efficiency. The test subjects would focus on the command they want to give to the drone and accordingly the ML model will be checked for an output. An SVM classifier would be a best fit for this type of data.

This output will then be passed to an Arduino UNO which will then transmit it over to the drone via Bluetooth, after which desired movement will be made.

The advantage of our model over others would be a higher efficiency with a more advanced ML model as well as better filters which will pull out only desired information from the EEG signal to root out as much noise as possible.

Also our model will be wireless as it will use Bluetooth to connect to the drone.

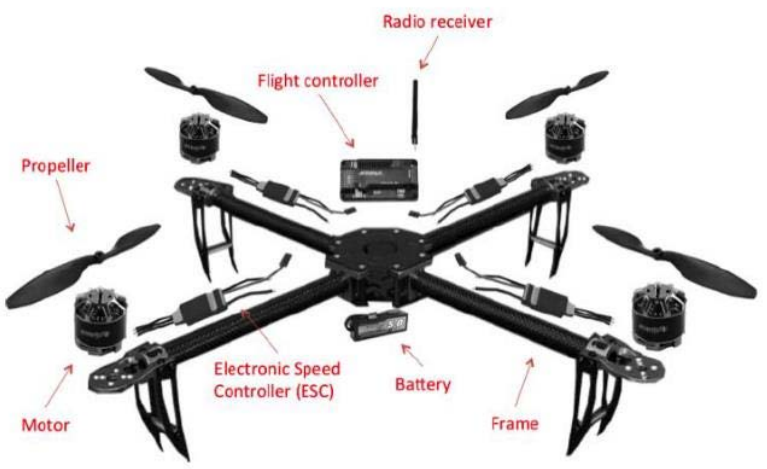

Figure 1. Architecture of a quadcopter

Figure1. Drone

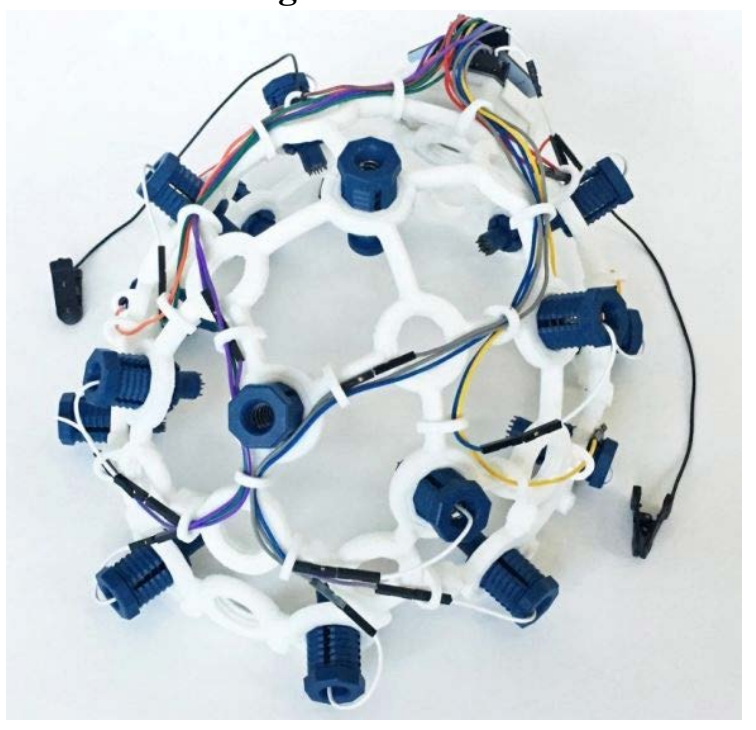

Figure2. Ultracortex markIV EEG headset 


\subsection{Block Diagrams}

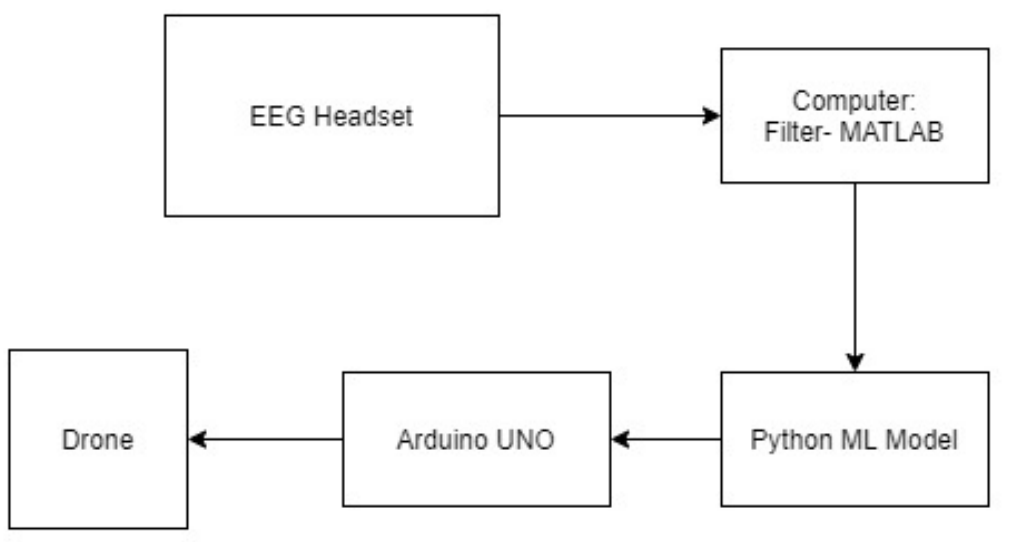

Figure3. Flow Chart

\section{Objectives}

We aim to create a system that:

1. To reduce human effort, using automation.

2. To demonstrate a downscaled application of BCI which can be used in various other fields which may revolutionise usage and scope of BCI.

3. To allow hands free and easy control of the drone.

4. To make a reliable and cost-effective solution for automation.

\section{Conclusion}

This paper includes the use of EEG waves for controlling a drone through BCI (Brainwaves) by using an Arduino. It is intended that this paper explains a person about the EEG waves and how to use them to control a drone with the help of a machine learning model and filters applied to the brainwaves, to achieve maximum efficiency. 
The future scope that the drone can be controlled more precisely using a commercial headset as it has more sensors and even by switching over to LABVIEW as a computer processing of the signals.

Additionally, we can implement some more features like increasing the speed of the drone. This project can be integrated with better technologies to enhance the use of artificial limbs, various implants to improve their efficiency and performance.

\section{Future Scope}

The future scope that the drone can be controlled more precisely using a commercial headset as it has more sensors and even by switching over to LABVIEW as a computer processing of the signals.

Additionally, we can implement some more features like increasing the speed of the drone.

This project can be integrated with better technologies to enhance the use of artificial limbs, various implants to improve their efficiency and performance.

\section{References}

[1] "Brainwave Controlled Wheelchair", Miss. Reshma Arote, Miss. Komal Nawale, Miss. Monika Shinde, Student, BE Computer, Prof. P. A. Bansode, Prof.V. B. Bhamare, Assistant Professor, Department Of Computer Engineering, SVCET, Rajuri Published in: Imperial Journal of Interdisciplinary Research (IJIR),Vol-3, Issue-12, (2017).

[2] "Prosthetic arm Controller Based on Brainwaves Spectrum EEG Sensor", Subrata Mukhopadhyay, Senior Member, IEEE, EEE/ECE Department, Guru Tegh Bahadur Institute of Technology, Published in: 2014 6th IEEE Power India International Conference (PIICON)

[3] "Brain Controlled Robot Car", Lin Zhou, Furong Li, Senior Member, IEEE, Chenghong Gu, ZechunHu, and Simon Le Blond, Member, IEEE, Published in: IEEE Transactions on Smart Grid (Volume-5, Issue-2, March 2014)

[4] "Brain Wave Controlled Drone", Shubham B. Parsewar, Pooja P.Polawar, Gayatree V. Paul, Department of Electronics and Communication Engineering, G. H. Raisoni Institute of Engineering and Technology Wagholi, Pune, Maharashtra, India, Published in: International Journal of Innovations in Engineering and Technology (IJIET), Volume-6, Issue-2, December-2015.

[5] "Controlling electrical devices with human brainwaves”, S.Valarmathy, R.Ramani, S.Selvaraju, G.Ramachandran, Associate Professors /ECE, Fahim Akhtar, Student /ETCE, V.M.K.V Engg College, Salem, TN, India, Published in: I.J. Intelligent Systems and Applications, October-2013.

[6] "Drone Control based on Mental Commands and Facial Expressions", A.N.Madur, P.N.Matte, Department of Electronics and Telecommunication Engineering, Published in: International Journal of Engineering Research and Technology (IJERT), Vol-2, Issue-10, October-2013 